\title{
REVIEW
}

\section{Kinetics of engraftment following allogeneic hematopoietic cell transplantation with reduced-intensity or nonmyeloablative conditioning}

\author{
Frédéric Baron ${ }^{\mathrm{a}}$, Marie-Térèse Little ${ }^{\mathrm{a}}$, Rainer Storb ${ }^{\mathrm{a}, \mathrm{b}, *}$ \\ a Clinical Research Division, Fred Hutchinson Cancer Research Center, 1100 Fairview \\ Ave N, D1-100, P.O. Box 19024, Seattle, WA, USA \\ b University of Washington School of Medicine, Seattle, WA 98109-1024, USA
}

\section{KEYWORDS \\ Hematopoietic cell transplantation; Nonmyeloablative; Chimerism; \\ Engraftment}

\begin{abstract}
Summary Nonmyeloablative or reduced-intensity conditioning regimens have been used to condition elderly or ill patients with hematological malignancies for allogeneic hematopoietic cell transplantation (HCT). Initial mixed donor/host chimerism (i.e. the coexistence of hematopoietic cells of host and donor origin) has been observed in most patients after such transplants. Here, we describe both factors affecting engraftment kinetics in patients given a nonmyeloablative or a reduced-intensity conditioning, and associations between peripheral blood cell subset chimerism levels and HCT outcomes.

(C) 2004 Elsevier Ltd. All rights reserved.
\end{abstract}

Reduced-intensity and nonmyeloablative conditioning regimens for allogeneic HCT

To avoid serious regimen-related toxicities, the use of conventional allogeneic hematopoietic cell transplantation (HCT) has been restricted to

Corresponding author. Tel.: +44-206-667-4470/4875; fax: +44-206-667-6124.

E-mail addresses: fbaron@fhcrc.org (F. Baron), mlittle@ fhcrc.org (M.-T. Little), rstorb@fhcrc.org (R. Storb). younger and medically fit patients. ${ }^{1}$ This is unfortunate since the median age at diagnosis for patients with hematological malignancies such as acute and chronic leukemias, lymphomas, multiple myeloma or myelodysplastic syndromes, ranges from 65 to 70 years, ${ }^{2}$ thereby precluding the use of allogeneic HCT for most patients with these diseases. The curative potential of allogeneic HCT has been ascribed not only to the eradication of malignant cells by high-dose chemotherapy and total body irradiation, but also to immune-mediated graft-versustumor (GVT) effects. ${ }^{3-5}$ The power of the 
Table 1 Examples of reduced-intensity or nonmyeloablative conditioning regimens.

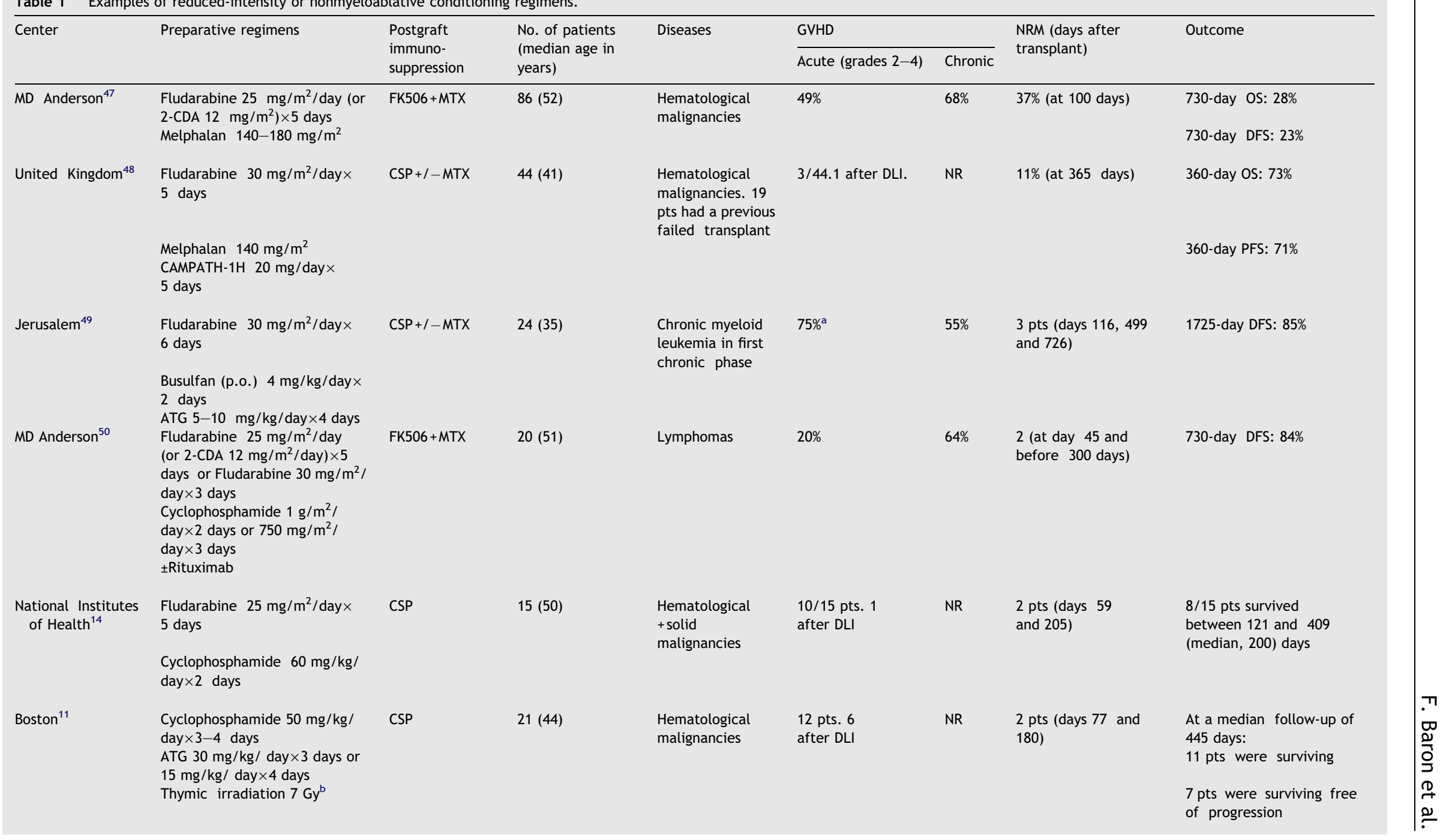




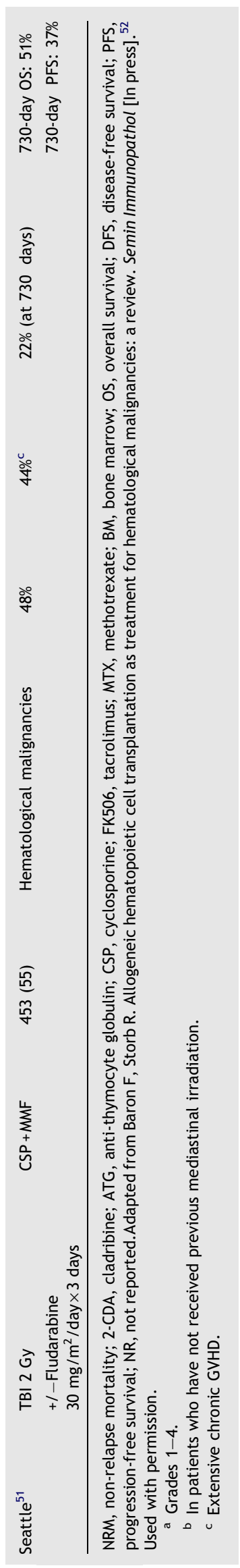

lymphocyte-mediated GVT effects has led several groups of investigators to explore the curative potential of donor lymphocyte infusions (DLI) in patients who had relapsed with hematological malignancies after allogeneic HCT. ${ }^{6,7}$ The induction of durable remissions by DLI in a number of patients demonstrated that GVT effects were capable of eradicating hematological malignancies, even in the absence of chemotherapy.

In an attempt to extend the use of allogeneic HCT to older patients and those with comorbid conditions, several groups of investigators have explored allogeneic HCT after reduced-intensity ${ }^{8-10}$ or truly nonmyeloablative conditioning regimens ${ }^{11-14}$ in which the burden of tumour eradication was shifted toward GVT effects.

Examples of reduced-intensity or truly nonmyeloablative conditioning regimens are shown in Table 1. Many of the regimens did not meet criteria of nonmyeloablative conditioning which have included: (1) no eradication of host hematopoiesis, (2) prompt endogenous hematologic recovery ( $<4$ weeks) without transplant and (3) presence of mixed chimerism upon allogeneic engraftment. Analogous to conventional regimens, reducedintensity regimens produce major anti-tumor effects and reduce host-versus-graft reactions. In contrast, nonmyeloablative regimens rely on optimization of pre- and post-transplant immunosuppression to overcome host-versus-graft reactions and allow allogeneic engraftment, thereby setting the stage for eradication of tumors by GVT effects. In patients with slowly progressing diseases (e.g. chronic lymphocytic leukemia, low-grade nonHodgkin lymphoma, or chronic myeloid leukemia in first chronic phase) or with more aggressive diseases in complete remission, a nonmyeloablative conditioning regimen might be sufficient to achieve engraftment and cure the malignant disease. However, cytoreduction might be required in patients with aggressive diseases, e.g. acute leukemia, multiple myeloma, high-grade lymphoma, Hodgkin disease, who are not in complete remission at the time of the transplant.

After extensive pre-clinical studies in a dog model, ${ }^{15}$ we have developed a nonmyeloablative conditioning regimen consisting of low-dose (2 Gy) total body irradiation $(\mathrm{TBI}) \pm$ fludarabine 30 $\mathrm{mg} / \mathrm{m}^{2} /$ days $\times 3$ days to condition elderly or ill patients with hematological malignancies for allogeneic HCT. $^{12}$ Postgrafting immunosuppression consisted of mycophenolate mofetil (MMF) and cyclosporine (CSP) (Fig. 2). The clinical trials were carried out jointly by a group of collaborators located at the Fred Hutchinson Cancer Research Center, University of Washington, Children's Hospital 
and Regional Medical Center, and Veterans Administration Medical Center, all in Seattle, WA, USA; Stanford University, Palo Alto, CA, USA; City of Hope National Medical Center, Duarte, CA, USA; University of Leipzig, Germany; University of Colorado, Denver, CO, USA; University of Torino, Italy; University of Arizona, Tucson, AZ, USA; Baylor University, Dallas, TX, USA; University of Utah, Salt Lake City, UT, USA; Oregon Health Sciences University, Portland, OR, USA; and, more recently, the Medical College of Wisconsin, Milwaukee, WI, USA; and Emory University, Atlanta, GA, USA. The transplant regimen was remarkably well tolerated, with the majority of patients receiving their transplants in the outpatient setting. ${ }^{12,16,17}$

\section{Mixed chimerism after allogeneic HCT following myeloablative conditioning}

The term "chimerism" has referred to the presence of lympho-hematopoietic cells of donor origin after an allogeneic HCT, ${ }^{18}$ and "full or complete chimerism"' has been defined as complete replacement of host by donor lympho-hematopoiesis. For practical reason, mixed chimerism was defined as the detection of $5-95 \%$ cells of donor origin in hematopoietic tissues, which approximately defined the sensitivity of routinely used assays for quantifying chimerism.

Mixed chimerism was first observed in patients with advanced acute leukemia conditioned with cyclophosphamide alone. ${ }^{19}$ In patients with aplastic anemia conditioned with high doses of cyclophosphamide with or without anti-thymocyte globulin (ATG), mixed host/donor chimerism was found in a substantial proportion of patients, and this was associated with higher risk of graft rejection and, in the patients with sustained engraftment, a lower risk of acute GVHD. ${ }^{20,21}$ Branch et al. ${ }^{22}$ and Petz et al. ${ }^{23}$ reported mixed chimerism in some patients with hematologic malignancies transplanted with unmodified marrow grafts after myeloablative conditioning. In these studies, the presence of mixed chimerism did not predict subsequent disease relapse. However, Mackinnon et al. ${ }^{24}$ showed that minimal residual disease was more common in chronic myeloid leukemia (CML) patients with mixed chimerism, and Huss et al. ${ }^{21}$ reported that the presence of mixed chimerism after day 100 was associated with increased relapse risks in CML patients. In addition, mixed chimerism has been found frequently in patients who received $\mathrm{T}$-cell-depleted grafts after myeloablative conditioning, ${ }^{25}$ indirectly implying that the recipients' lympho-hematopoiesis was eradicated not only by the conditioning regimens but also by donor T cells.

\section{Methods for chimerism assessment}

Several methods have been employed to determine the degree of donor engraftment after allogeneic $\mathrm{HCT}$, including conventional and molecular cytogenetics (for sex mismatched donor-recipient pairs or for patients with diseases that carry cytogenetic abnormalities), immunoglobulin allotypes, erythroid cell antigens, leukocyte isoenzymes, fluorescence in situ hybridization (FISH), and variable number tandem repeat (VNTR) polymorphism analyses (Table 2). ${ }^{18}$ As for the latter, certain core DNA sequences are tandemly dispersed and repeated throughout the genome, and the number of the tandem repeats of the core sequences can vary between individuals. Repeats can be composed of "microsatellite"' (also called short tandem repeats or STR) sequences of 2-8 bp in length and repeated up to 100 times, ${ }^{26,27}$ or of "minisatellites" sequences of $8-50 \mathrm{bp}$ in length. ${ }^{28,29}$ These repeated core sequences within a locus are characterized by extensive polymorphism and Mendelian codominant inheritance. ${ }^{30,31}$ Polymorphic microsatellite and minisatellite markers have advantages over techniques that detect sex chromosomes in that they can be used for virtually all donor-recipient pairs and, when used in combination with DNA amplification by polymerase chain reaction (PCR) techniques, only small numbers of cells are required for the test. As a result, microsatellites and minisatellites have been used extensively as markers of engraftment and for evaluation of the degree of chimerism in marrow transplantation in dogs and humans. ${ }^{32-34}$ For quantification, PCR products have been electrophoresed on an agarose gel, hybridized with ${ }^{32} \mathrm{P}$-labeled probes, autoradiographed and quantified by phosphor imaging (Fig. 1) or PCR was carried out with fluorescently labeled primers and the PCR product visualized using the $A B I 310$ sequencer (Applied Biosystems, Foster City, CA). Depending on fragment length and efficiency of amplification, the sensitivity of these assays is between $0.1 \%$ and $5 \% .^{18,35}$

Short insertion/deletion polymorphisms detectable by quantitative real-time PCR have been introduced as alternatives to VNTR or STR markers for monitoring chimerism levels after HCT. ${ }^{36}$ Singlenucleotide polymorphisms (SNPs) that occur on average at every $1.3 \mathrm{~kb}$ in the human genome are thought to be the most common type of genetic variation, and the use of a multiplex microarray- 
Table 2 Methods for determining chimerism.

\begin{tabular}{|c|c|c|c|c|}
\hline Assay (reference) & $\begin{array}{l}\text { Probability of two- } \\
\text { way informative } \\
\text { markers with sibling } \\
\text { pairs (\%) }\end{array}$ & $\begin{array}{l}\text { Assay } \\
\text { sensitivity (\%) }\end{array}$ & $\begin{array}{l}\text { Quantitative } \\
\text { accuracy }\end{array}$ & Disadvantages \\
\hline Erythrocyte antigens $^{53}$ & $75-80$ & $0.1-0.5$ & Moderate & $\begin{array}{l}\text { - Studies limited to the } \\
\text { erythroid lineage }\end{array}$ \\
\hline Isoenzymes ${ }^{53}$ & 95 & $10-30$ & Moderate & $\begin{array}{l}\text { - Low sensitivity } \\
\text { - Technical difficulty }\end{array}$ \\
\hline Conventional cytogenetics ${ }^{53}$ & 50 & $10-20$ & Low & $\begin{array}{l}\text { - Low sensitivity } \\
\text { - Low accuracy } \\
\text { - Studies limited to cells } \\
\text { in metaphase }\end{array}$ \\
\hline $\mathrm{FISH}^{53}$ & 50 & $1-2$ & High & $\begin{array}{l}\text { - Only available for sex-mismatch } \\
\text { HCT (or when an informative } \\
\text { autosomal marker is present) } \\
\text { - Age-association loss of the Y } \\
\text { chromosome in cells from older male } \\
\text { - Y chromosome loss in tumor cells }\end{array}$ \\
\hline RFLP ${ }^{53}$ & 97 & $10-20$ & Moderate & $\begin{array}{l}\text { - Technical difficulty } \\
\text { - High DNA requirement } \\
\text { - Radioactivity }\end{array}$ \\
\hline VNTR/STR ${ }^{53}$ & $90-100$ & $5-10$ & Low & - Low quantitative accuracy \\
\hline VNTR/STR with phosphorimaging ${ }^{54}$ & $90-100$ & $0.1-1$ & Moderate & - Radioactivity \\
\hline Multiplex STR amplification and fluorescence detection ${ }^{55}$ & $90-100$ & $1-5$ & High & - \\
\hline Real-time PCR STR amplification ${ }^{56}$ & $90-100$ & $0.1-1$ & High & - \\
\hline Multiplex SNP genotyping ${ }^{36}$ & 99-100 & 1 & High & - Technical difficulty \\
\hline
\end{tabular}


$\mathrm{R} \quad \mathrm{D} \mathrm{CD}^{+} \mathrm{CD}^{+} \mathrm{CD}^{+}$Mono NK Gran $\underline{\mathrm{CD}^{+}} \mathrm{Gran}_{\mathrm{CD}}{ }^{+} \mathrm{CD} 4^{+} \mathrm{CD} 8^{+}$Mono NK Gran

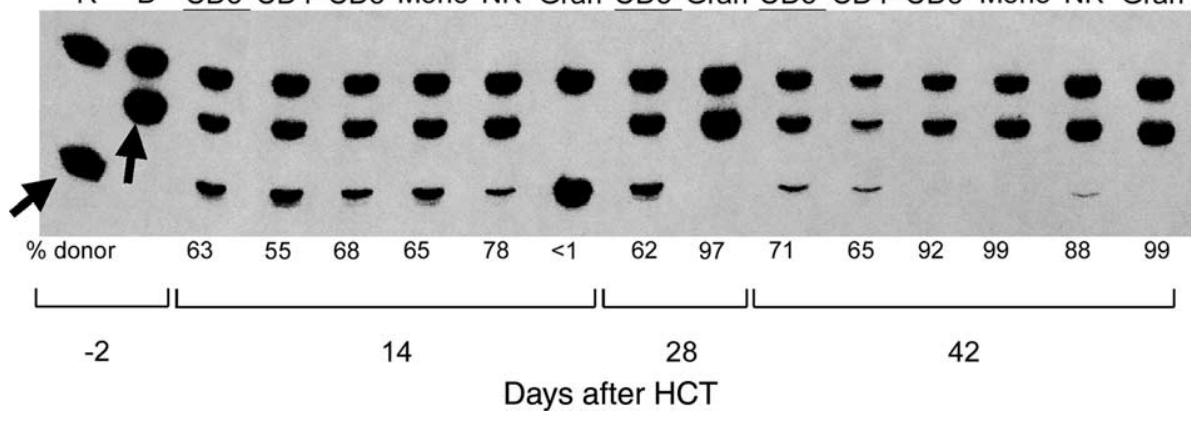

Figure 1 Engraftment kinetics in a patient receiving an allogeneic transplant after a nonmyeloablative conditioning regimen of Fludarabine and $2 \mathrm{~Gy}$ TBI for a metastatic renal cell carcinoma. Phosphor image analyses of the donorspecific bands and host-specific bands were used to quantify the percentage of donor cells. Cells were separated using anti CD3 FITC, anti-CD3 TC, anti-CD4 PE, anti-CD8 FITC, anti-CD14 TC, anti-CD56 PE and anti-CD45-labeled monoclonal antibodies. $\mathrm{R}$, recipient; $\mathrm{D}$, donor; $\mathrm{CD}^{+}, \mathrm{CD}^{+} \mathrm{T}$ cells; $\mathrm{CD}^{+}, \mathrm{CD}^{+} \mathrm{T}$ cells; $\mathrm{CD}^{+}, \mathrm{CD}^{+} \mathrm{T}$ cells; Mono, mononuclear cells; NK, NK cells; Gran, granulocytes.

based minisequencing system screening 51 SNPs was recently shown to provide accurate chimerism quantification.

\section{Engraftment after nonmyeloablative or reduced-intensity conditioning regimens}

\section{Kinetics of engraftment}

With the exception of cyclophosphamide-conditioned patients with aplastic anemia, ${ }^{20}$ engraftment after nonmyeloablative conditioning regimen was first analyzed by Childs et al. ${ }^{14}$ in 15 patients conditioned with cyclophosphamide and fludarabine and given postgrafting immunosuppression with CSP. The patterns of engraftment varied considerably but most often full donor chimerism was achieved earlier in T cells than in granulocytes, and the achievement of full donor T-cell chimerism preceded acute GVHD and anti-tumor responses. The kinetics of B-cell recovery were distinct from those of myeloid and T-cell lineages, while natural killer (NK) cell chimerism was closely correlated with T-cell chimerism.

Ueno et al. ${ }^{37}$ studied chimerism evolution in 23 patients with metastatic tumors transplanted after a reduced-intensity conditioning regimen consisting of fludarabine and melphalan. Postgrafting immunosuppression included tacrolimus and short methotrexate. All patients showed 100\% T-cell and granulocyte chimerisms on days 30 and 100 after the transplant.

Dey et al. ${ }^{38}$ analyzed engraftment kinetics in 42 patients with advanced hematologic malignancies receiving allogeneic $\mathrm{HCT}$ after a regimen consisting of cyclophosphamide, anti-thymocyte globulin and thymic irradiation (the latter was given only to those patients who had not received previous mediastinal irradiation). Postgrafting immunosuppression consisted of a short course of CSP. On day 30, median T-cell chimerism was 50\% (range, $1-95 \%)$. Nineteen evaluable patients subsequently achieved full donor T-cell chimerism, and 14 rejected their transplant by day 100 after HCT.

We analyzed the kinetics of donor engraftment in various peripheral blood cell subpopulations and their relation to HCT outcomes in a cohort of 120 patients given grafts from HLA-matched related or unrelated donors after conditioning consisting of $2 \mathrm{~Gy} \mathrm{TBI} \pm$ fludarabine, $30 \mathrm{mg} / \mathrm{m}^{2} /$ day. Postgrafting immunosuppression included MMF plus $\operatorname{CSP}^{39}$ (Fig. 2). While most patients rapidly developed high degrees of donor engraftment, they remained mixed donor/host chimeras for up to 6 months after HCT (Fig. 3). Generally, donor T-cell

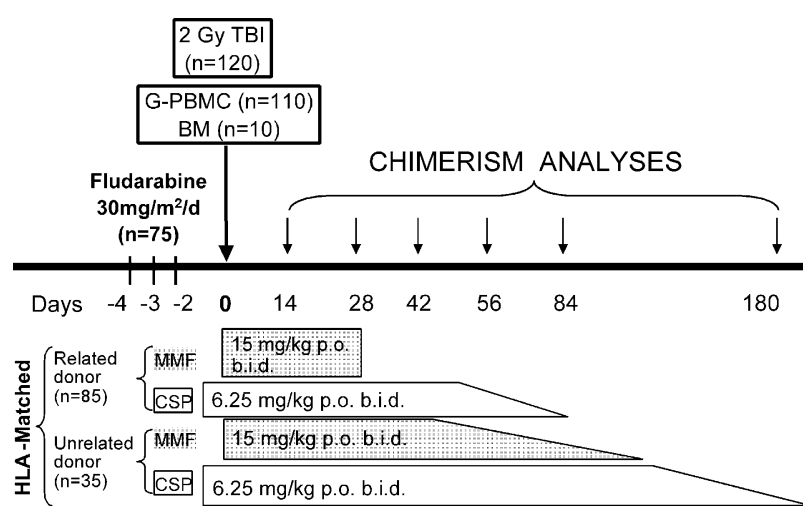

Figure 2 Schedule of study evaluating engraftment kinetics in 120 patients receiving allogeneic HCT following nonmyeloablative conditioning. TBI, total body irradiation; MMF, mycophenolate mofetil; CSP, cyclosporine; G-PBMC, G-CSF-mobilized peripheral blood mononuclear cells; BM, bone marrow. 


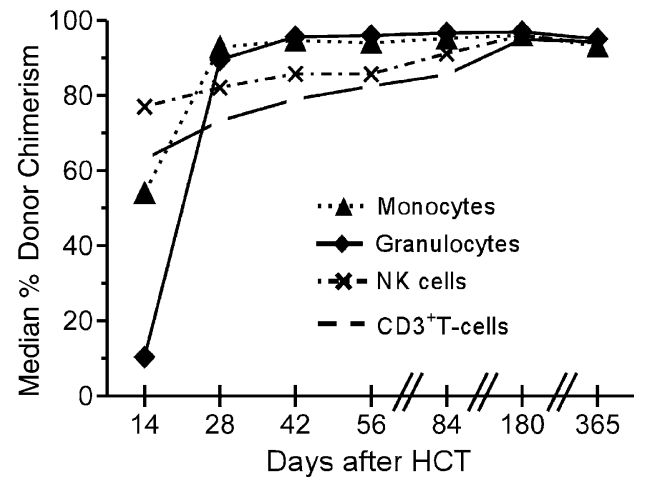

Figure 3 Kinetics of engraftment after HCT with a nonmyeloablative conditioning consisting of $2 \mathrm{~Gy} \mathrm{TBI}$ with or without fludarabine $30 \mathrm{mg} / \mathrm{m}^{2} /$ day $\times 3$ days. Median percentages of donor chimerism among peripheral blood cell subsets in HLA-matched related G-CSF mobilized peripheral blood mononuclear cell recipients $(n=85)$.

chimerism lagged behind myeloid chimerism. Donor T-cell chimerism on day 14 and 28 after HCT correlated closely with both donor $\mathrm{CD}^{+}(R=0.94)$ and $\mathrm{CD}^{+} \mathrm{T}$-cell subset $(R=0.90)$ chimerism levels. Correlations between donor T-cell content and those among granulocytes $(R=0.37)$, NK cells $(R=0.66)$ and monocytes $(R=0.56)$ were weaker at the same time points.

\section{Associations between transplant variables and chimerism levels}

In addition to the intensity of the conditioning regimen, several other variables have been associated with chimerism levels after allogeneic HCT. These variables either influenced the recipients' immune competence, thereby altering host-versus-graft reactions, or the donor T-cells and, therewith, graft-versus-host reactions.

\section{Variables affecting host-versus-graft reactions}

\section{Previous chemotherapy}

Several reports have shown relationships between previous chemotherapy exposure and chimerism levels. Valcarcel et al. ${ }^{40}$ studied 68 patients transplanted after conditioning with fludarabine (30 $\mathrm{mg} / \mathrm{m}^{2}$ on days -8 to -4$)$ and melphalan $(70 \mathrm{mg} /$ $\mathrm{m}^{2}$ on days -3 and -2 ) in patients with lymphoid malignancies or fludarabine $\left(30 \mathrm{mg} / \mathrm{m}^{2}\right.$ on days -9 to -5 ) and busulfan (total $10 \mathrm{mg} / \mathrm{kg}$ ) in patients with myeloid malignancies. GVHD prophylaxis consisted of CSP and a short course of methotrexate (MTX). In multivariate analysis, having received more than two lines of chemotherapy pretransplant was significantly associated with complete donor chimerism on day 30 after HCT among unfractionated nucleated peripheral blood cells.

Carvallo et al. ${ }^{41}$ analyzed pre-transplant variables affecting chimerism levels in 36 patients with metastatic solid tumors conditioned with fludarabine/busulfan. Postgrafting immunosuppression consisted of CSP alone or CSP combined with either MMF or MTX. At day 30, median T-cell and granulocyte chimerism levels were $98 \%$ and $76 \%$, respectively, in patients who had prior chemotherapy versus $88 \%(p=0.008)$ and $26 \%(p<0.0001)$, respectively, in patients who had not.

In our study, a univariate analysis of data from patients who had received intensive chemotherapy before HCT showed higher donor T-cell, granulocyte, and monocyte chimerism levels $(p=0.002$, 0.002 and 0.01 , respectively), compared to those who did not. ${ }^{39}$ There was also a trend towards higher donor NK cell chimerism $(p=0.10)$. In multivariate analysis, intensive chemotherapy before HCT was associated with higher T-cell $(p=0.002$, average $21 \%$ increase compared to no chemotherapy) and monocyte ( $p=0.04$, average $15 \%$ increase compared to no chemotherapy) chimerism levels.

\section{Hematologic disease category}

We also analyzed the impact of underlying hematologic diseases on engraftment kinetics. Patients with MDS and CML had lower levels of T-cell chimerisms than patients with AML or with lymphoid malignancies $(p=0.03) .{ }^{39}$ After adjusting for intensive previous chemotherapy, the impact on disease category on T-cell chimerism levels was no longer significant.

\section{Variables affecting graft-versus-host reactions}

\section{Stem cell source/graft composition}

Patients who received marrow as stem cell source had lower percentages of donor T-cell chimerism $(p=0.002)$ and a trend to lower donor NK-cell chimerism $(p=0.10)$ than patients who received GCSF-mobilized peripheral blood mononuclear cells (G-PBMC) (Fig. 4).

Carvallo et al. found that $\mathrm{CD} 34^{+}$graft content positively correlated with the degree of donor myeloid chimerism, but failed to establish a correlation between graft composition and donor T-cell chimerism levels.

Baron et al. analyzed T-cell chimerism in 35 patients conditioned with TBI (2 Gy) alone $(N=15)$, TBI (2 Gy) and fludarabine $(N=13)$, or fludarabine 


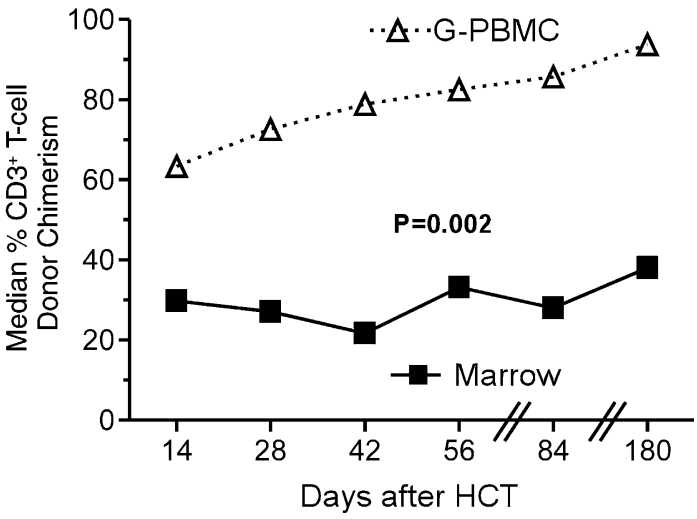

Figure 4 Kinetics of donor T-cell engraftment in patients receiving G-CSF mobilized peripheral blood mononuclear cells (G-PBMC, $n=110$ ) or bone marrow (marrow, $n=10$ ) as stem cell sources.

and cyclophosphamide $(N=7)$. Patients received either unmanipulated- $(N=18)$, CD8-depleted$(N=11)$ or CD34-selected-G-PBMC $(N=6)$. Postgrafting immunosuppression included MMF and CSP. Median donor T-cell contributions on days 28, 60, 100,180 and 365 in recipients of unmanipulated G-PBMC were $75 \%, 85 \%, 87 \%, 90 \%$ and $100 \%$, respectively. Evolution of donor T-cell chimerism did not differ significantly between recipients of unmanipulated versus CD8-depleted G-PBMC while CD34 selection resulted in significantly decreased donor T-cell chimerism ${ }^{42}$ (Fig. 5).

We also found significant correlations between graft contents and levels of donor chimerisms. ${ }^{39}$ Higher T-cell $(p=0.003)$, NK cell $(p=0.03)$ and monocyte $(p=0.0002)$ contents in the graft were associated with higher T-cell donor chimerisms, while higher $\mathrm{CD}^{+} 4^{+}$cell $(p=0.002)$ and monocyte $(p=0.04)$ contents resulted in higher monocyte donor chimerism. In multivariate analysis, higher numbers of monocytes in the graft $(p=0.005$, modeled as a continuous linear variable) were associated with increasing donor T-cell chimerism.

\section{Donor type}

We found no differences in chimerism levels among patients who received HLA-matched related compared to unrelated G-PBMC. ${ }^{39}$

\section{Associations between chimerism levels and HCT outcomes after reduced-intensity or nonmyeloablative conditioning}

\section{Graft rejection}

An increased incidence of graft rejection in aplastic anemia patients with mixed donor/host chimerism after conditioning with cyclophosphamide

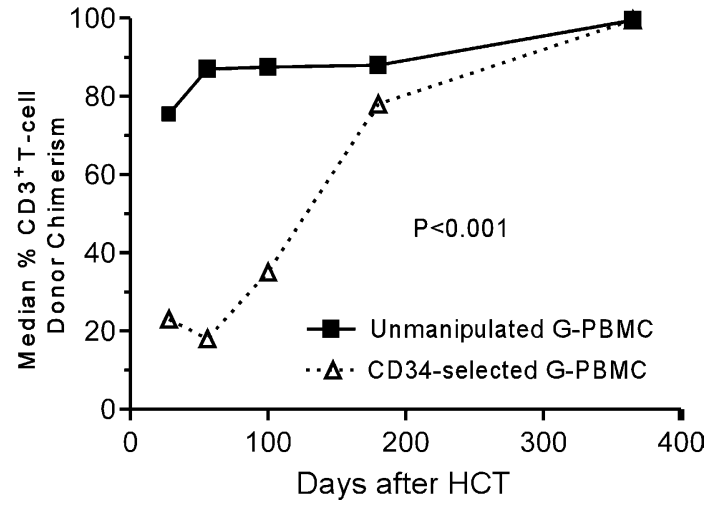

Figure 5 Kinetics of donor T-cell engraftment in patients receiving unmanipulated $(n=18)$ or CD34selected $(n=6)$ G-CSF mobilized peripheral blood mononuclear cells (G-PBMC) as stem cell sources after nonmyeloablative regimens consisting of $\mathrm{TBI}$ alone $(n=10), \mathrm{TBI}+$ fludarabine $(n=10)$ or cyclophosphamide plus fludarabine $(n=4)$. Adapted from Baron F, SchaafLafontaine N, Humblet-Baron S, et al. T-cell reconstitution after unmanipulated, CD8-depleted or CD34-selected nonmyeloablative peripheral blood stem-cell transplantation. Transplantation 2003;76:1705-13 [reference 42]. Used with permission.

was first reported in $1986 .{ }^{20}$ Few studies to date have analyzed the impact of lineage-specific chimerism levels on graft rejection. Bornhauser et al. $^{43}$ suggested that fludarabine/busulfanconditioned patients with NK-cell donor chimerism levels below $75 \%$ on days $10-30$ after HCT were more likely to have graft failure than those with more than $75 \%(p=0.03)$. However, NK-cell chimerism levels were available in only 10 patients. Matthes-Martin et al. ${ }^{44}$ showed that day $28 \mathrm{~T}$-cell $(p=0.001)$ and NK-cell $(p<0.0001)$ chimerism levels were strongly correlated with late graft rejection in pediatric patients conditioned with a reduced-intensity regimen. In contrast, granulocyte/monocyte chimerism was less reliable in predicting graft rejection.

In our study, both day-14 NK- and T-cell chimerism levels $<50 \%$ were associated with significantly increased risks of subsequent graft rejection $(p=0.01$ and $p=0.02$, respectively, after adjusting for donor type (related versus unrelated)) (Table 3$){ }^{39}$

\section{Graft-versus-host disease}

A decreased incidence of acute GVHD in patients with sustained engraftment and mixed donor/host chimerism was first reported in aplastic anemia patients conditioned with cyclophosphamide. ${ }^{20}$ More recently, Childs et al. ${ }^{14}$ reported that achievement of complete donor T-cell chimerism always preceded grade 2-4 acute GVHD. However, Mattson 
Table 3 Association between day-14 donor chimerism levels and graft rejection.

\begin{tabular}{|c|c|c|c|}
\hline \multirow[t]{2}{*}{$\%$ donor chimerism ${ }^{\mathrm{b}, \mathrm{c}}$ on day 14} & \multicolumn{3}{|c|}{$\%$ of patients with rejection (\# pts at risk) } \\
\hline & T cells & NK cells & Granulocytes \\
\hline $0-50$ & $25(n=32)$ & $33(n=18)$ & $10(n=81)$ \\
\hline $51-75$ & $2.5(n=40)$ & $5(n=19)$ & $0(n=4)$ \\
\hline $76-90$ & $0(n=22)$ & $0(n=35)$ & $0(n=6)$ \\
\hline $91-100$ & $0(n=6)$ & $0(n=14)$ & $0(n=5)$ \\
\hline$p$ value $^{a}$ & $p=0.02$ & $p=0.01$ & $p=0.05$ \\
\hline
\end{tabular}

et al. found that $90 \%$ of their patients (conditioned with four nonmyeloablative regimens, including fludarabine, busulfan, TBI, cyclophosphamide and ATG) had mixed donor/host T-cell chimerism at the onset of acute GVHD.

Petersen et al. ${ }^{45}$ proposed that donor $\mathrm{CD} 8^{+} \mathrm{T}$ cell count above the median $\left(0.043 \times 10^{6}\right.$ cells $\left./ \mu \mathrm{l}\right)$ on day 14 after HCT predicted the risk of subsequent development of grade 2-4 acute GVHD. However, only 24 patients were included in that study.

We showed that, with increasing levels of donor $\mathrm{T}$-cell chimerisms on day 28 , the probability of subsequent grade 2-4 acute GVHD increased. The risk of subsequent development of acute GVHD was $27 \%$ in patients with T-cell chimerism levels of $\leqslant 50 \%$, but was $75 \%$ in patients with $>90 \%$ T-cell chimerism levels ( $p=0.02$ after adjusting for donor type). As observed by Mattson et al., most patients with grades 2 and 3-4 acute GVHD were mixed donor/ host chimeras at onset of GVHD.

\section{Graft-versus-tumor effect/relapse}

Two recent reports suggested a relationship between chimerism levels and disease responses. ChiIds et al. reported that achievement of $100 \%$ donor $\mathrm{T}$-cell engraftment always preceded anti-tumor responses. Perez-Simon et al. found a trend for a higher relapse risk in patients with mixed $\mathrm{T}$-cell chimerism as compared to patients with complete donor chimerism after conditioning with fludarabine/melphalan or fludarabine/busulfan.

In our study, 93 of 120 patients had measurable malignant disease before transplantation, and 41 of the $93(44 \%)$ achieved complete remissions 199 (range, 28-963) days after HCT. At the time of achievement of complete remissions, 19 of the 41 patients showed mixed donor/host T-cell chimerism and 22 had complete donor T-cell chimerism. Neither day $28 \mathrm{~T}$-cell nor NK-cell chimerism levels were significantly associated with disease re- sponses, although there was a suggestion that patients with T-cell chimerism levels $<50 \%$ were at higher risk of failing to achieve complete remissions ( $20 \%$ versus $47 \%$, not significant).

\section{Progression-free survival}

Keil et al. ${ }^{46}$ found an improved progression-free survival in patients with $>90 \%$ donor T-cell chimerism compared to those with $<90 \%(p<0.002)$ after conditioning with $2 \mathrm{~Gy} \mathrm{TBI}$ plus fludarabine.

In our study, there were no correlations between early cell subset chimerism levels and progressionfree survival. However, when chimerism data from days 14-100 were combined, higher donor NK cell chimerism levels were associated with statistically significantly improved progression-free survival [HR $0.79,95 \% \mathrm{Cl}(0.64-0.96), p=0.02]$.

\section{Summary}

Engraftment kinetics after nonmyeloablative or reduced-intensity conditioning depend on the intensity of pretransplant chemotherapy, the intensity of the conditioning regimens, the graft composition, and whether grafts have been depleted of $T$ cells. Monitoring mixed chimerism among peripheral blood subpopulation early after transplant identified patients at risk for graft rejection, acute GVHD, and death/relapse, and this knowledge might allow early intervention with immunosuppressive drugs or DLI aimed at obviating these complications.

\section{Practice points}

- Kinetics of donor engraftment are different among $\mathrm{T}$ cells, NK cells, granulocytes and monocytes. 
- Patients given intensive preceding therapy have higher granulocyte, T-cell and monocyte donor chimerism levels.

- G-PBMC as a stem cell source is associated with increased T-cell donor chimerism levels.

- Day-14 T- and NK-cell chimerism levels predicted patients at risk for subsequent graft rejection.

- Day-28 T-cell chimerism levels predicted patients at risk for subsequent GVHD.

\section{Research agenda}

- Engraftment kinetics of naive and memory T cells.

- Impact of CD4 and CD8 T-cell chimerism on subsequent risks of rejection/GVHD.

- Impact of chimerism levels on progressionfree survival in a large group of patients with similar diseases.

\section{Acknowledgement}

This work was supported by Grants CA78902, CA18029, CA15704, DK42716 and HL36444 of the National Institutes of Health, Bethesda, MD. Frédéric Baron is Research Assistant of the National Fund for Scientific Research (FNRS) Belgium and supported in part by postdoctoral grants from the Fulbright Commission. We thank Bonnie Larson and Helen Crawford for help with manuscript preparation.

\section{References}

1. Baron F, Storb R, Little M-T. Hematopoietic cell transplantation: five decades of progress (Review). Arch Med Res 2003;34:528-44.

2. Molina AJ, Storb RF. Hematopoietic stem cell transplantation in older adults. In: Rowe JM, Lazarus HM, Carella AM, editors. Handbook of Bone Marrow Transplantation. London, UK: Martin Dunitz Ltd; 2000. p. 111-37.

3. Weiden PL, Flournoy N, Thomas ED, Prentice R, Fefer A, Buckner CD, et al. Antileukemic effect of graft-versus-host disease in human recipients of allogeneic-marrow grafts. $N$ Engl J Med 1979;300:1068-73.

4. Sullivan KM, Weiden PL, Storb R, Witherspoon RP, Fefer A, Fisher $\mathrm{L}$, et al. Influence of acute and chronic graftversus-host disease on relapse and survival after bone marrow transplantation from HLA-identical siblings as treatment of acute and chronic leukemia. Blood 1989;73:1720-8.

5. Riddell SR, Berger C, Murata M, Randolph S, Warren EH. The graft versus leukemia response after allogeneic hematopoietic stem cell transplantation. Blood Rev 2003;17:153-62.

6. Kolb HJ, Schattenberg A, Goldman JM, Hertenstein B, Jacobsen N, Arcese W, et al. Graft-versus-leukemia effect of donor lymphocyte transfusions in marrow grafted patients. European group for blood and marrow transplantation working party chronic leukemia. Blood 1995;86:2041-50.

7. Collins RHJ, Shpilberg O, Drobyski WR, Porter DL, Giralt S, Champlin R, et al. Donor leukocyte infusions in 140 patients with relapsed malignancy after allogeneic bone marrow transplantation. J Clin Oncol 1997;15:433-44.

8. Slavin S, Nagler A, Naparstek E, Kapelushnik Y, Aker M, Cividalli $G$, et al. Nonmyeloablative stem cell transplantation and cell therapy as an alternative to conventional bone marrow transplantation with lethal cytoreduction for the treatment of malignant and nonmalignant hematologic diseases. Blood 1998;91:756-63.

9. Giralt S, Estey E, Albitar M, van Besien K, Rondón G, Anderlini $P$, et al. Engraftment of allogeneic hematopoietic progenitor cells with purine analog-containing chemotherapy: harnessing graft-versus-leukemia without myeloablative therapy. Blood 1997;89:4531-6.

10. Khouri IF, Keating $M$, Körbling $M$, Przepiorka D, Anderlini $P$, O'Brien S, et al. Transplant-lite: induction of graft-versusmalignancy using fludarabine-based nonablative chemotherapy and allogeneic blood progenitor-cell transplantation as treatment for lymphoid malignancies. J Clin Oncol 1998;16:2817-24.

11. Spitzer TR, McAfee S, Sackstein R, Colby C, Toh HC, Multani $P$, et al. Intentional induction of mixed chimerism and achievement of antitumor responses after nonmyeloablative conditioning therapy and HLA-matched donor bone marrow transplantation for refractory hematologic malignancies. Biol Blood Marrow Transplant 2000;6:309-20.

12. McSweeney PA, Niederwieser D, Shizuru JA, Sandmaier BM, Molina AJ, Maloney DG, et al. Hematopoietic cell transplantation in older patients with hematologic malignancies: replacing high-dose cytotoxic therapy with graft-versustumor effects. Blood 2001;97:3390-400.

13. Childs R, Chernoff A, Contentin N, Bahceci E, Schrump D, Leitman S, et al. Regression of metastatic renal-cell carcinoma after nonmyeloablative allogeneic peripheral-blood stem-cell transplantation. N Engl J Med 2000;343:750-8.

14. Childs R, Clave E, Contentin N, Jayasekera D, Hensel N, Leitman $\mathrm{S}$, et al. Engraftment kinetics after nonmyeloablative allogeneic peripheral blood stem cell transplantation: full donor T-cell chimerism precedes alloimmune responses. Blood 1999;94:3234-41.

15. Storb R, Yu C, Wagner JL, Deeg HJ, Nash RA, Kiem H-P, et al. Stable mixed hematopoietic chimerism in DLA-identical littermate dogs given sublethal total body irradiation before and pharmacological immunosuppression after marrow transplantation. Blood 1997;89:3048-54.

16. Niederwieser D, Maris M, Shizuru JA, Petersdorf E, Hegenbart U, Sandmaier BM, et al. Low-dose total body irradiation (TBI) and fludarabine followed by hematopoietic cell transplantation (HCT) from HLA-matched or mismatched unrelated donors and postgrafting immunosuppression with cyclosporine and mycophenolate mofetil (MMF) can induce durable complete chimerism and sustained remissions in patients with hematological diseases. Blood 2003;101: 1620-9. 
17. Maris MB, Niederwieser D, Sandmaier BM, Storer B, Stuart $M$, Maloney $\mathrm{D}$, et al. HLA-matched unrelated donor hematopoietic cell transplantation after nonmyeloablative conditioning for patients with hematologic malignancies. Blood 2003;102:2021-30.

18. Antin JH, Childs R, Filipovich AH, Giralt S, Mackinnon S, Spitzer T, et al. Establishment of complete and mixed donor chimerism after allogeneic lymphohematopoietic transplantation: recommendations from a workshop at the 2001 Tandem Meetings (Review). Biol Blood Marrow Transplant 2001;7:473-85.

19. Santos GW, Sensenbrenner LL, Burke PJ, Colvin M, Owens $\mathrm{AH} \mathrm{Jr}$, Bias WB, et al. Marrow transplantation in man following cyclophosphamide. Transplant Proc 1971;3:400-4.

20. Hill RS, Petersen FB, Storb R, Appelbaum FR, Doney K, Dahlberg $\mathrm{S}$, et al. Mixed hematologic chimerism after allogeneic marrow transplantation for severe aplastic anemia is associated with a higher risk of graft rejection and a lessened incidence of acute graft-versus-host disease. Blood 1986;67:811-6.

21. Huss R, Deeg HJ, Gooley T, Bryant E, Leisenring W, Clift R, et al. Effect of mixed chimerism on graft-versus-host disease, disease recurrence, and survival after HLA-identical marrow transplantation for aplastic anemia or chronic myelogenous leukemia. Bone Marrow Transplant 1996;18:767-76.

22. Branch DR, Gallagher MT, Forman SJ, Winkler KJ, Petz LD, Blume KG. Endogenous stem cell repopulation resulting in mixed hematopoietic chimerism following total body irradiation and marrow transplantation for acute leukemia. Transplantation 1982;34:226-8.

23. Petz LD. Documentation of engraftment and characterization of chimerism following bone marrow transplantation. In: Forman SJ, Blume KG, Thomas ED, editors. Bone Marrow Transplantation. Boston, MA: Blackwell Scientific Publications; 1994. p. 136-48.

24. Mackinnon S, Barnett L, Heller G, O'Reilly RJ. Minimal residual disease is more common in patients who have mixed T-cell chimerism after bone marrow transplantation for chronic myelogenous leukemia. Blood 1994;83: 3409-16.

25. Bretagne S, Vidaud M, Kuentz M, Cordonnier C, Henni T, Vinci $G$, et al. Mixed blood chimerism in T cell-depleted bone marrow transplant recipients: evaluation using DNA polymorphisms. Blood 1987;70:1692-5.

26. Weber JL, May PE. Abundant class of human DNA polymorphisms which can be typed using the polymerase chain reaction. Am J Hum Genet 1989;44:388-96.

27. Thiede C, Bornhauser M, Ehninger G. Evaluation of STR informativity for chimerism testing - comparative analysis of 27 STR systems in 203 matched related donor recipient pairs. Leukemia 2004; 18:248-54.

28. Jeffreys AJ, Wilson V, Thein SL. Hypervariable 'minisatellite' regions in human DNA. Nature 1985;314:67-73.

29. Boerwinkle E, Xiong WJ, Fourest E, Chan L. Rapid typing of tandemly repeated hypervariable loci by the polymerase chain reaction: application to the apolipoprotein B $3^{\prime}$ hypervariable region. Proc Natl Acad Sci USA 1989;86:212-6.

30. Koreth J, O'Leary JJ, O'D MCGee J. Microsatellites and PCR genomic analysis (Review). J Pathol 1996;178: 239-48.

31. Ostrander EA, Sprague Jr GF, Rine J. Identification and characterization of dinucleotide repeat $(\mathrm{CA})_{n}$ markers for genetic mapping in dog. Genomics 1993;16:207-13.
32. Yu C, Ostrander E, Bryant E, Burnett R, Storb R. Use of (CA $)_{n}$ polymorphisms to determine the origin of blood cells after allogeneic canine marrow grafting. Transplantation 1994;58:701-6.

33. Lawler M, Humphries P, McCann SR. Evaluation of mixed chimerism by in vitro amplification of dinucleotide repeat sequences using the polymerase chain reaction. Blood 1991;77:2504-14.

34. Oberkircher AR, Strout MP, Herzig GP, Fritz PD, Caligiuri MA. Description of an efficient and highly informative method for the evaluation of hematopoietic chimerism following allogeneic bone marrow transplantation. Bone Marrow Transplant 1995;16:695-702.

35. Storb R, Yu C, McSweeney P. Mixed chimerism after transplantation of allogeneic hematopoietic cells. In: Thomas ED, Blume KG, Forman SJ, editors. Hematopoietic Cell Transplantation. 2nd ed. Boston: Blackwell Science; 1999. p. 287-95.

36. Fredriksson $M$, Barbany $G$, Liljedahl $U$, Hermanson $M$, Kataja M, Syvanen AC. Assessing hematopoietic chimerism after allogeneic stem cell transplantation by multiplexed SNP genotyping using microarrays and quantitative analysis of SNP alleles. Leukemia 2004;18: 255-66.

37. Ueno NT, Cheng YC, Rondon G, Tannir NM, Gajewski JL, Couriel DR, et al. Rapid induction of complete donor chimerism by the use of a reduced-intensity conditioning regimen composed of fludarabine and melphalan in allogeneic stem cell transplantation for metastatic solid tumors. Blood 2003;102:3829-36.

38. Dey BR, McAfee S, Colby C, Sackstein R, Saidman S, Tarbell $\mathrm{N}$, et al. Impact of prophylactic donor leukocyte infusions on mixed chimerism, graft-versus-host disease, and antitumor response in patients with advanced hematologic malignancies treated with nonmyeloablative conditioning and allogeneic bone marrow transplantation. Biol Blood Marrow Transplant 2003;9:320-9.

39. Baron F, Baker JE, Storb R, Gooley TA, Sandmaier B, Maris M et al. Kinetics of engraftment in patients with hematological malignancies given allogenic hematopoietic cell transplantation after nonmyeloablative conditioning. Blood 2004; doi:10.1182/blood-2004-04-1506.

40. Valcarcel D, Martino R, Caballero D, Mateos MV, PerezSimon JA, Canals C, et al. Chimerism analysis following allogeneic peripheral blood stem cell transplantation with reduced-intensity conditioning. Bone Marrow Transplant 2003;31:387-92.

41. Carvallo C, Geller N, Kurlander R, Srinivasan R, Mena O, Igarashi $\mathrm{T}$, et al. Prior chemotherapy and allograft $\mathrm{CD} 34^{+}$ dose impact donor engraftment following nonmyeloablative allogeneic stem cell transplantation in solid tumor patients. Blood; Prepublished online October 9, 2003; doi:10.1182/ blood-2003-04-1170.

42. Baron F, Schaaf-Lafontaine N, Humblet-Baron S, Meuris N, Castermans E, Baudoux E, et al. T-cell reconstitution after unmanipulated, CD8-depleted or CD34-selected nonmyeloablative peripheral blood stem-cell transplantation. Transplantation 2003;76:1705-13.

43. Bornhauser M, Thiede C, Platzbecker U, Jenke A, Helwig $\mathrm{R}$, Plettig $\mathrm{R}$, et al. Dose-reduced conditioning and allogeneic hematopoietic stem cell transplantation from unrelated donors in 42 patients. Clin Cancer Res $2001 ; 7: 2254-62$.

44. Matthes-Martin S, Lion T, Haas OA, Frommlet F, Daxberger $\mathrm{H}$, Konig $\mathrm{M}$, et al. Lineage-specific chimaerism after stem cell transplantation in children following reduced intensity conditioning: potential predictive value of NK 
cell chimaerism for late graft rejection. Leukemia 2003;17:1934-42.

45. Petersen SL, Madsen HO, Ryder LP, Svejgaard A, Masmas TN, Dickmeiss $E$, et al. Chimerism studies in HLA-identical nonmyeloablative hematopoietic stem cell transplantation point to the donor CD8 T-cell count on day +14 as a predictor of acute graft-versus-host disease. Biol Blood Marrow Transplant 2004; 10:337-46.

46. Keil F, Prinz E, Moser K, Mannhalter C, Kalhs P, Worel N, et al. Rapid establishment of long-term culture-initiating cells of donor origin after nonmyeloablative allogeneic hematopoietic stem-cell transplantation, and significant prognostic impact of donor T-cell chimerism on stable engraftment and progression-free survival. Transplantation 2003;76:230-6.

47. Giralt S, Thall PF, Khouri I, Wang X, Braunschweig I, Ippolitti $C$, et al. Melphalan and purine analog-containing preparative regimens: reduced-intensity conditioning for patients with hematologic malignancies undergoing allogeneic progenitor cell transplantation. Blood 2001;97: 631-7.

48. Kottaridis PD, Milligan DW, Chopra R, Chakraverty RK, Chakrabarti S, Robinson S, et al. In vivo CAMPATH-1H prevents graft-versus-host disease following nonmyeloablative stem cell transplantation. Blood 2000;96: 2419-25.

49. Or R, Shapira MY, Resnick I, Amar A, Ackerstein A, Samuel S, et al. Nonmyeloablative allogeneic stem cell transplantation for the treatment of chronic myeloid leukemia in first chronic phase. Blood 2003;101:441-5.

50. Khouri IF, Saliba RM, Giralt SA, Lee M-S, Okoroji G-J, Hagemeister FB, et al. Nonablative allogeneic hematopoi- etic transplantation as adoptive immunotherapy for indolent lymphoma: low incidence of toxicity, acute graft-versushost disease, and treatment-related mortality. Blood 2001;98:3595-9.

51. Sandmaier BM, Maris M, Maloney DG, Gooley TA, Stuart MJ, Hegenbart $U$, et al. Low-dose total body irradiation (TBI) conditioning for hematopoietic cell transplants (HCT) from HLA-matched related (MRD) and unrelated (URD) donors for patients with hematologic malignancies: a five-year experience. Blood 2003;102(Part 1):78a-9a. \#264.

52. Baron F, Storb R. Allogeneic hematopoietic cell transplantation as treatment for hematological malignancies: a review. Semin. Immunopathol. [in press].

53. Bryant E, Martin PJ. Documentation of engraftment and characterization of chimerism following hematopoietic cell transplantation. In: Blume KG, Forman SJ, Appelbaum FR, editors. Thomas Hematopoietic Cell Transplantation. Oxford, UK: Blackwell Publishing Ltd.; 2004. p. 234-43.

54. McDaniel DO, Naftilan J, Barber WH. Limiting detection of an amplification signal for HLA-D region and VNTR genes by 32P-PCR. Biotechniques 1993;15:140-5.

55. Thiede C, Florek M, Bornhäuser M, Ritter M, Mohr B, Brendel $C$, et al. Rapid quantification of mixed chimerism using multiplex amplification of short tandem repeat markers and fluorescence detection. Bone Marrow Transplant 1999;23:1055-60.

56. Alizadeh M, Bernard M, Danic B, Dauriac C, Birebent B, Lapart C, et al. Quantitative assessment of hematopoietic chimerism after bone marrow transplantation by realtime quantitative polymerase chain reaction. Blood 2002;99:4618-25.

Available online at www.sciencedirect.com

science@irect 